EESTI NSV TEADUSTE AKADEEMIA TOIMETISED. 19. KÖIDE KEEMIA * GEOLOOGIA. 1970, Nr. 1

ИЗВЕСТИЯ АКАДЕМИИ НАУК ЭСТОНСКОИ ССР. ТОМ 19

ХИМИЯ * ГЕОЛОГИя. 1970, №

\title{
ХИМИЧЕСКОЕ ИСПОЛЬЗОВАНИЕ ПРИБАЛТИИСКОГО СЛАНЦА - ЗВЕНО В ЛЕНИНСКОМ ПЛАНЕ КОМПЛЕКСНОГО ОСВОЕНИЯ ПРИРОДНЫХ БОГАТСТВ СТРАНЫ
}

В программе народнохозяйственного строительства Советского государства, разработка которой была предпринята под руководством В. И. Ленина вскоре после Октябрьской революции, большое внимание уделено рациональному использованию природных богатств страны. Этим вопросам посвящены известные работы В. И. Ленина - «Очередные задачи Советской власти» и «Набросок плана научно-технических работ», относящиеся к марту и апрел! 1918 г. [ $\left.{ }^{1}\right]$. В них путеводной нитью являются два принципиальных положения, до настоящего времени играющие роль ключевых в развитии советской экономики.

Первое из них своднтся к необходимости планового и систематического р а сши рения сырьев ой баз в стране, начиная с поиска и кончая освоением новых природных богатств. Второй, не менее важный принцип заключается в обязательности ко м плексн ого и спольз ов а н и я сырьевых ресурсов.

Эти положения В. И. Ленин неизменно учитывал в своей деятельности, в частности при решении острейших для того времени вопросов снабжения страны всеми видами топлива и химическим сырьем. Особен"но хочется подчеркнуть, что применительно к горючи м сланца м провозглашенные В. И. Лениным принципы использования природных богатств были претворены в жизнь при его личном участии $\left[{ }^{2}\right]$.

В литературе эта страница истории отечественной топливно-химической промышленности и энергетики освещена сравнительно скудно, и на ней, не рискуя повторением известных истин, можно остановиться несколько подробнее.

Как известно, горючие сланцы в дореволюционной России не получили практического применения, хотя в 1916 г. в Эстонии и Петрограде были проведены крупные, промышленного масштаба, работы по добыче сланца-кукерсита, его сжиганию в топке парового котла и газифика цин [3]. Это событие оценивается сейчас как первый шаг в создании отечественной сланцевой промышленности.

Впервые же потенциальные возможности, связанные с комплексным использованием этого «нового» вида горючих ископаемых, были реализованы после обсуждения доклада и предложений И. М. Губкина на заседании Ссвнаркома под председательством В. И. Ленина [1] в июле 1918 г.* В итоге по инициативе и указанию Владимира Ильича в том же

* Здесь и далее ссылки на архивные источники приведены по материалам публикации $\left[{ }^{2}\right]$. 
году в системе Высшего Совета Народного Хозяйства был создан Главный комитет по горючим сланцам. Деятельность последнего положила начало реальному созданию и функционированию советской сланцевой промышленности. К 1919 г. относится организация промышленной добычи сланцев на Веймарнском (Ленинградская область) и Ундорском, близ Симбирска, участках Прибалтийского и Приволжского месторождений. Она была существенно расширена в 1920 г., при создании нового сланцевого района в Кашпире, близ Сызрани.

Основные направления в использовании сланца, которое в концу первой половины 20-х годов уже приобрело комплексный характер, стали складываться по мере роста его добычи. Так, дополнительно к применению сланца в качестве топлива на промышленных предприятиях (неизбежному в условиях гражданской войны и отрыва районов Поволжья и Северо-Запада от основной топливной базы) в плане ГОЭЛРО было предусмотрено стронтельство Саратовской и Сызранской электростанций на сланцах [5]. В 1919-1920 гг. на базе термической переработки волжского сланца под Москвой было организовано в сравнительно небольшом масштабе производство ряда химических продуктов, в том числе ихтиола. В марте 1920 г. Ленин дал указание Главсланцу о строительстве сланцеперегонного завода в Поволжье, в непосредственной близости к району добычи сырья [6].

Пристальное внимание, уделяемое В. И. Лениным созданию сланцевой промышленности, ее освоению и развитию, нашло отражение, например, в его письмах - И. М. Губкину в 1921 г., где он предлагает опубликовать сведения об успехах в добыче сланца [7], и в ВСНХ в октябре 1922 г., в котором дана высокая оценка деятельности ученых и организаторов сланцевой промышленности и сформулированы предложения по ее дальнейшему развитию $\left.{ }^{8}\right]$. Следует добавить, что, согласно опубликованным сведениям, добыча и использование сланца в упомянутых выше районах страны оказались экономически более выгодными, чем применение привозных нефти и угля $\left.{ }^{2}\right]$.

Эта краткая историческая справка показывает, в какой мере инициатива В. И. Ленина способствовала вовлечению горючих сланцев в сырьевую и топливную базу Советского Союза в качестве нового компонента, насколько принцип комплексного использования их оказался плодотворным и реальным даже в невероятно трудных условиях гражданской войны и блокады. Напомним, что степень изученности свойств этого каустобиолита и возможности его использования (в том числе и химического) в 20-е годы были сравнительно невелики. Ленинская оценка горючих сланцев и принципа их комплексного использования в последующем, по мере развития науки и техники, получила еще более существенное подтверждение.

В свете сказанного целесообразно охарактеризовать в общем виде потенциальные возможности и перспективы комплексного использования прибалтийских сланцев не только как местного энергетического топлива, но и как ценного источника химического сырья, проследить за претворением в жизнь ленинских принципов в наше время, через 40-45 лет после выступления В. И. Ленина, в условиях Советской Прибалтики и, в частности, Эстонской ССР.

Предварительно подчеркнем, что в буржуазной Эстонии промышленное использование сланца, в силу сложившейся конъюнктуры в небольшом капиталистическом государстве, подверженном воздействию экономических кризисов, в условиях грозовой предвоенной обстановки в Восточной Европе, не могло носить комплексного характера. Сланцевая промышленность была призвана удовлетворять минимальные потребно- 
сти в топливе маломощной энергетики, ряда небольших промышленных предприятий и, частично, железнодорожного трапспорта. Назначением же звена термической переработки кукерсита являлось производство искусственных жидких топлив (бензин, керосин, мазут) и битумов, которые в 20-30-х годах имели более или менее устойчивый сбыт даже в периоды общего экономического спада. Поэтому развитие в Эстонии научных исследований, направленных на изучение сланца как источника химического сырья (отличающихся значительной сложностью, потребностью в высококвалифицированных ученых и больших расходах на создание и оборудование лабораторий), в довоенный период не имело под собой экономической основы.

Первоочередной задачей исследовательских работ, предпринятых в Советской Эстонии в первые послевоенные годы, являлось содействие восстановлению и совершенствованию сланцевой промышленности, разрушенной фашистскими оккупантами, восстановлению в прежнем, хотя и расширенном направлении преимущественного производства искусст венных топлив, жидких и газообразных. Это отвечало острой потребности в них промышленности и населения крупного и высокоразвитого Северо-западного района СССР. Тем не менее, начиная с конца 40-х годов деятельность коллектива ученых-химиков, в том числе и Института химии Академии наук ЭССР, в значительной части была направлена на подготовку основы для химического использования сланца и сланцепродуктов - одного из главных и наименее разработанных звеньев в комплексном использовании этого важнейшего природного богатства республики.

Для решения этой важной и нелегкой задачи предстояло: организо. вать углубленное изучение химической природы и генезиса органической массы (керогена) кукерсита; заново пересмотреть на основе точного эксперимента сложившиеся ранее представления о механизме термического разложения сланца с целью резкого повышения химической эффекгивности этого процесса; оценить или уточнить ряд технологических свойств сланца, ранее недостаточно изученных, и создать основу для совершенствования существующих и разработки новых высокоэффективных технологических процессов его переработки; глубоко исследовать тонкий состав продуктов термического и химического (см. ниже) распада керогена; выявить возможности выделения из сложной смеси сланцепродуктов тех компонентов, которые с наибольшей эффективностью могут быть использованы в качестве сырья для химического синтеза; раз. работать научную основу методов, направленных на выпуск наиболее ценных и дефицитных химических продуктов, препаратов и материалов. Этот круг задач, по объему и диапазону аналогичный задачам, решенным химической технологией нефти или угля, сравнительно немногочисленному коллективу эстонских химиков - ученых, исследователей и производственников - в ряде случаев в кооперации с исследователями нз братских республик, удалось решить в основном за 50-е и первую половину $60-$ х годов.

В настоящей статье обзорно-исторического характера не имеет смысла цетально останавливаться на характеристике и оценке комплекса провєденных научных исследований. Сошлемся лишь на материалы, посвященные развитию науки о сланцах за 25 лет существования Совет. ской Эстонии [9. 10], и на обобщающие труды в этой области, в том числе сотрудников Института химии АН ЭССР, изданные в последние 5-6 лет $\left[^{11-14}\right]$.

На развитие и направление указанного комплекса научных исследований на разных его этапах, естественно, накладывали отпечаток, а 
иногда и существенные ограничения, изменения в народно-хозяйственной конъюнктуре страны в целом и Северо-западного района СССР, в частности. Такие осложнения возникли в первую очередь в конце 50 -х годов в связи с громадным прогрессом техники и экономики разведки, добычи и транспорта нефти и природных газов. Надобность в решении вопросов использования сланцепродуктов в качестве моторных топлив и в других заменителях продуктов переработки дешевой нефти постепенно, а затем и окончательно отпала. Переработка сланцев получила экономический стимул лишь в тех направлениях, которые не связаны с обычными возможностями нефтегазохимической промышленности и могут, по тем или иным причинам, конкурировать по всем показателям с последней.

На следующем, более близком к настоящему времени этапе работу химиков и перспективу химического использования сланца весьма осложнил резкий рост потребности республики и края в электрической и тепловой энергии, обусловленный значительным повышением их промышленного потенциала, тенденцией к максимальной электрификации сельского хозяйства и возросшими бытовыми потребностями населения. В связи с этим использование кукерсита в качестве сравнительно дешевого, хотя и малоквалифицированного местного энергетического топлива и резкий рост мощностей теплоэлектростанций в Советской Эстонии не только в последние годы, но и в предстоящие $10-15$ лет представляются первоочередными в сравнении с развитием сланцевой химии. Более того, создание ряда химических производств на базе сланцевого сырья в силу большой их энергоемкости может оказаться нерациональным впредь до упорядочения энергетической проблемы. Таким образом, жизнеспособными в ближайшие годы могут оказаться те способы химического использования сланца и сланцепродуктов, которые по своим показателям не только конкурируют или совмещаются с переработкой нефти или газа, но и не связаны со значительным потреблением электрической и тепловой энергии.

Описанные препятствия, как нам представляется, могут быть преодолены при развитии следующих направлений использования сланца.

Перв ое направление заключается во всемерной химизации существующей промышленности термической переработки сланца и в использовании специфических свойств выпускаемой ею (в сравнительно небольшом масштабе) продукции. Из разработанных в рамках этого направления и внедряемых в промышленность методов укажем прежде всего на комплекс технологических процессов подготовки сланцевой смолы, выделения из легкосредней фракции ее олефиновых углеводородов и синтеза на их основе поверхностно-активных веществ. Научная основа совместного производства моющих веществ - алкиларилсульфонатов (сульфонолов) и алкилсульфатов (аналогов типола) разработана в Институте химии АН ЭССР. Внедрение его уже завершается пуском нового промышленного цеха на сланцехимическом комбинате «Кивиыли». Заметную роль призвано сыграть использованию ароматических углеводородов, получаемых при пиролизе камерного газбензина (часть из них будет потреблена на месте для производства сульфонола). Исходный процесс и получение продуктов высокой чистоты успешно освоены сланцеперерабатывающим комбинатом им. В. И. Ленина в Кохтла-Ярве.

Известная часть тяжелых фракций смолы после соответствующей очистки составляет сырье для производства электродного кокса на основе коксования в кубах (работы Института сланцев и СПК им. Ленина). Эффективно осуществлен в промышленности синтез клеевых смол на базе водорастворимых «сланцевых» фенолов - метод разработан и внедрен коллективом химиков Таллинского политехнического института 
и сланцехимических предприятий; организовано и полноценно эксплуатируется производство на той же сырьевой основе синтетических дубителей (Институт сланцев и сланцехимический комбинат «Кивиыли»).

Основной этап развития исследований и работ по внедрению в аспекте этого направления, как видно из сказанного, близок в настоящее время к завершению. Дальнейшее же развитие в его составе исследований и работ по внедрению навряд ли окажется интенсивным. Известная перспектива расширения фронта таких работ открывается благодаря наметившемуся использованию некоторых фракций смолы полукоксования сланца для изготовления сельскохозяйственных препаратов типа нэрозина, предназначенных для борьбы с ветровой эррозией почвы, подвиж. ными песками, некоторыми заболеваниями растений и пр. (Институт химии АН ЭССР, Институт сланцев, сланцехимический комбинат «Кивиыли» и ряд специализированных организаций сельскохозяйственного и биологического профиля) .

В торое направление заключается в организации комплексного энергохимического (или, как его называют, энерготехнологического) использования сланца. Оно базируется на термической переработке кукерсита с применением агрегатов большой мощности и распределением получаемых сланцепродуктов между крупномасштабной энергетикой и химической промышленностью. Такое распределение, точнее его пропорции, определяются ценностью тех или иных продуктов как химического сырья или квалифицированного (т. е. высококалорийного, малосернистсго и беззольного) энерготоплива; с другой стороны, характер его зависит от потребности края на данном этапе в электротепловой энергии или в химических продуктах.

Направление это приобретает особую актуальность в связи с упомянутым опережающим развитием сланцевой энергетики. Уже сейчас более $85 \%$ добываемого в Прибалтийском бассейне сланца либо непосредственно, либо в виде сланцепродуктов используется в качестве топлива в большой и малой энергетике, на транспорте, в быту.

Высокоинтенсивное сжигание пылевидного сланца непосредственно в топках современных котлоагрегатов связано с рядом серьезных трудностей, обусловленных специфическими свойствами этого многозольного топлива (эррозия и загрязнение теплообменной аппаратуры). Они не только значительно ухудшают к.п.д. и условия эксплуатации теплоэлектростанций, но и ограничивают мощность отдельных котлоагрегатов. А это отражается на конкурентоспособности «сланцевой» энергетики по отношению к ГРЭС, работающей на облагороженных топливах и угле. Развитию ее препятствует и интенсивное загрязнение атмосферы пылевыми выбросами и серой, борьба с которыми до настоящего времени остается малоэффективной.

Указанные трудности и недостатки могут быть преодолены при переходе к энергохимическому использованию кукерсита. Не требует специальных пояснений факт резкого повышения к.п.д. электростанций при снабжении их облагороженным и высококачественным жидким и газообразным топливом, возможность существенного упрощения энергоблоков и снижения капитальных затрат в энергетическом звене энергохимического комплекса. Однако к технике термической переработки сланца в этом случае предъявляются новые и чрезвычайно жесткие требования. Технологический процесс должен отличаться высокой интенсивностыо и химической эффективностью, а агрегаты - большой мощностью и повышенным к.п.д. Использование для этой цели традиционных способов и агрегатов маловероятно. Например, для обеспечения работы типовой ГРЭС по энерготехнологической схеме необходимо соорудить свыше 
сотни газогенераторов при условии, что мощность каждого из них по сланцу будет доведена со 130-150 до 500 тонн в сутки. При этом такое же количество сланцевой мелочи так или иначе подвергнется сжиганию в энергоустановках, иобо генераторы потребляют кусковой сланец. Химический к.п.д. генераторного процесса относительно невысок $(73-75 \%)$. Сушественную долю продуктов составляет низкокалорийный газ, нс пригодный для снабжения крупных энергоустановок. Роль химического сырья в таком комплексе смогут играть лишь водорастворимые фенолы.

Изложенным требованиям в большей мере отвечает смоляной вариант метода термической переработки зернистого сланца с твердым теплоносителем (Энергетический институт им. Г. М. Кржижановского, Институт химии АН ЭССР, Институт сланцев, сланцехимический комбинат «Кивиыли» и ряд других организаций). Достоинствами метода являются высокая интенсивность теплоотдачи и скорость прогрева сланца, полнота использования в системе его горючей части; это обеспечивает достаточно высокие (свыше $80 \%$ ) химический и энергетический к.п.д. и большую мощность агрегатов, которая может превысить 1 млн. тонн слан山а в год. Продукты полукоксования могут быть использованы в качестве химического сырья: этилен, пропилен, бутилены из газа - для разнообразных видов органического синтеза; газбензин и бензиновая фракция смолы - для пиролиза с целью удвоения ресурсов низших олефинов и получения бензольных углеводородов $\left[{ }^{13}\right]$. Уточняется эффективнссть применения «смоляных» олефинов для синтеза ПАВ. В зависимости от конъюнктуры уровень отбора химического сырья может гибко варьироваться - от $2-7$ до $24-25 \%$ от суммы сланцепродуктов по потенциальному теплу; напомним, что в нефтепереработке он обычно не превышает $3-5 \%$. Экономическая эффективность такого комплекса в разных вариантах получила положительную оценку. Қак это ни парадоксально, при нынешней ситуации наиболее выгоден вариант с максимальным потреблением продуктов в энергетическом звене. Отметим в заключение, что осушествление такого комплекса практически снимает с повестки дня вопрос о загрязнении воздушного бассейна.

В свете сказанного выше нам представляется, что со временем энергохимический принцип станет основой для одного из главных путей развития техники использования сланца. В настоящее время подготовлены все материалы для его постепенного внедрения. Добавим, что метод переработки сланца с твердым теплоносителем завоевывает передовые позиции и непосредственно в сланцехимической промышленности как замена традиционных, но устаревших способов и агрегатов.

Т ре тье направление, по своему существу еще более отличное от традиционных направлений использования сланца, заключается в непосредственной химической переработке органического вещества сланца путем воздействия на него не термическими, а химическими агентами. В рамках этого направления в настоящее время разрабатываются два спссоба окисления керогена сланца.

Созданию этого направления предшествовал комплекс работ теоретического характера по изучению химической природы керогена кукерсита (Ннститут химии АН ЭССР; см. [1']) путем окисления его разными агенгами в различных средах, при различных глубине и интенсивности воздействня. Эти исследования наряду с результатами теоретического характера привели к заключению о возможности окисления значительной части керогена в специально подобранных условиях до смеси двухосновных насыщенных кислот с числом атомов углерода в основной цепи от четырех до десяти, т. е. главным образом от янтарной до себациновой. Последние представляют собой ценное сырье для химического синтеза 
высококачественных пластификаторов, термоустойчивых пластических масс и жестких пеноматериалов, а также производства сырья для синтетических волокон.

Исследователями Института химии АН ЭССР выбран принцип и разработана в полупромышленном масштабе химическая технология непрерывного многоступенчатого окисления обогащенного (до содержания органического вещества $80-90 \%$ ) сланца-кукерсита слабой азотной кислотой и кислородом воздуха под неболышчм давлением и при невысокой температуре. В итоге разработки выдан технологический регламент для организации опытно-промышленного производства. Выход смеси сырых дикарбоновых кислот определен в $75-82 \%$ по весу от керогена; хромагографируемые из них кислоты составляют около $60-65 \%$. Разработана гехнология раздельного получения янтарной кислоты и двух видов очищенных смесей дикарбоновых кислот: $\mathrm{C}_{4}-\mathrm{C}_{10}$ и кристаллических $\mathrm{C}_{5}-\mathrm{C}_{10}$ (в ссновном адипнновой, пробковой, пимелиновой и глутаровой). Побочный продукт - полифункциональные кислоты с выходом от керогена около $18 \%$ - предложено использовать для производства ростового вещества для сельского хозяйства. В настоящее время ведутся совместно с рядом научных учреждений исследования k опытные работы по очистке, разделению и использованию кислот и их смесей для химического синтеза.

Экономическая оценка такого комплекса оказалась положительной. Она свидетельствует о том, что новое направление может успешно конкурировать с производством аналогичного сырья не только в сельском хозяйстве, но и в нефтегазохимической промышленности и позволяет отказаться от импорта дорогостоящего сырья, трудно поддающегося переработке.

Второй способ, предложенный Ленинградским химико-технологическим институтом им. Ленсовета, не прошел еще столь детальной полупромышленной проработки. Он предусматривает окисление обогащенного сланца кислородом воздуха в щелочной среде, с последующей ее нейтрализацией минеральной кислотой. Пока еще трудно судить об экономических показателях этого метода; известно лишь, что на данном этапе выход дикарбоновых и полифункциональных кислот от керогена сравнительно невелик.

В настоящем кратком обзоре невозможно рассмотреть в деталях перспективу дальнейшего развития исследований и промышленного освоения всех звеньев комплексного использования прибалтийского сланца. Тем не менее, приведенные материалы дают яркое представление о том, в какой мере сформулированные В. И. Лениным принципы освоения и нспользования отечественных природных богатств получили развитие за истекшие годы и какова перспектива дальнейшего претворения в жизнь конкретных указаний Ленина.

\section{Л И ТЕРА Т У РА}

1. Л ен ин В. И., Сочинення, т. 27, с. 228.

2. Г ак А. М., Природа, № 4, 30 (1960).

3. С те п а н в И. И., Сланцевая и химическая промышленность, № 2-3, 3 (1966).

4. Центральный государственный архив Октябрьской революции и социалистического строительства (ЦГАОР), ф. 5446, оп. 31 , д. 26, л. $32-33$ (цит. по $\left[{ }^{2}\right]$ ).

5 К р жи жанов ски й Г. М., Об электрификации, 1921, с. 20-28.

6. Ленинский сборник, XXIV, с. 89. 
7. Ленинский сборник, XXIII, с. 106.

8. Л ен ин В. И., Сочинения, т. 35 , с. 476.

9. Сланцевая и химическая промышленность, № 3-4 (1965).

10. Академия наук Эстонской ССР в годы 1956-1964, Таллин, 1965, с. 99-123.

11. Фом и н а А. С. и др., Природа керогена прибалтийского горючего сланца-кукерси. та и его химические сырьевые качества, Таллин, 1965.

12. Фай нгольд С. И. и др., Синтетические моющие вещества из сланцевой смолы, Таллин, 1964.

13. Губергриц М. Я. и др., Термическая переработка сланца-кукерсита, Таллин, 1966.

14. Э й з ен О. Г., Методы анализа смол переработки твердого топлива и химический состав эстонской сланцевой смолы. Докторская диссертация, Институт химии Академии наук ЭССР, Таллин, 1967.

Ннститут химии

Академии наук Эстонской ССР

\section{Поступила в редакцию} $7 / \mathrm{X} 1969$ 